\title{
O Espírito Santo no atual paradigma tecnoeconômico das tecnologias da informação e comunicação: uma análise crítica a partir de dados sobre ciência, tecnologia e inovação*
}

\author{
Sávio Bertochi Caçador ${ }^{1}$ \\ Robson Antonio Grassi ${ }^{2}$
}

\begin{abstract}
Resumo: O presente artigo analisa a inserção da economia do Espírito Santo no atual paradigma tecnoeconômico. Este é caracterizado, sobretudo, pela inclusão das tecnologias da informação e da comunicação (TICs) no processo produtivo, pelos processos de aprendizado, de produção de conhecimento, cooperação e de inovação, no qual as regiões, por meio de suas empresas, instituições de ensino e pesquisa e organismos de apoio a tais atividades, exercem papel de relevância. O Espírito Santo, por sua vez, apesar de seu forte crescimento via industrialização nas últimas décadas, não logrou um desempenho satisfatório na produção de ciência, tecnologia e inovação (o que fica evidente, por exemplo, na comparação do desempenho destas atividades com a parcela do PIB nacional que a economia capixaba ocupa e na análise de dados como os da PINTEC), denotando uma inserção deficiente no paradigma das tecnologias da informação e comunicação. Apesar da criação recente de instituições de apoio à C,T\&I, os dados mostram que o estado continua seguindo um modelo de desenvolvimento baseado, sobretudo, na exploração de recursos naturais, com pouca produção de conhecimento via processos de cooperação e aprendizado, o que pode afetar seu potencial de crescimento no futuro, dados os limites ambientais e de espaço urbano característicos deste tipo de produção e também o fato de que algumas destas commodities, como o petróleo e o minério de ferro, são recursos não renováveis.
\end{abstract}

Palavras-chave: paradigma tecnoeconômico; desenvolvimento regional; Espírito Santo.

\footnotetext{
* Artigo financiado com recursos da Fundação de Apoio à Ciência e Tecnologia do Espírito Santo (FAPES). Agradecemos aos pareceristas anônimos pelos importantes comentários. Os erros remanescentes são de inteira responsabilidade dos autores.

${ }^{1}$ Economista do Instituto Euvaldo Lodi-Espírito Santo (IEL-ES) e Professor do Departamento de Economia da Universidade Federal do Espírito Santo (UFES).

${ }^{2}$ Professor do Mestrado em Economia da UFES.
} 


\title{
Espírito Santo State in today's techno- economic paradigm of information and communication technologies: $a$ critical analysis using data from science technology and innovation
}

\begin{abstract}
This paper examines the integration of Espírito Santo's economy in the current techno-economic paradigm. This is characterized, above all, by the inclusion of information and communication technologies (ICTs) in the production process, by the process of learning, production of knowledge, cooperation and innovation, in which the regions, through their firms, educational and research institutions, and agencies to support such activities, perform a relevant role. The Espírito Santo State, in turn, despite its strong growth through industrialization in recent decades, did not achieve a satisfactory performance in the production of science, technology and innovation (which is obvious, for example, in comparing the performance of these activities with the national GDP participation that the local economy plays and, in the analysis of data like Technological Innovation Survey - PINTEC), indicating a weak integration in the paradigm of information and communication technologies. Despite the recent creation of institutions to support S, T\& I, its data shows that the state is still following a model of development based, especially, in the exploitation of natural resources, with little production of knowledge through processes of cooperation and learning, which can affect their potential for growth in the future, given the environmental and urban limits that characterized this type of production and also the fact that some of these commodities, such as oil and iron ore, are non-renewable resources.
\end{abstract}

Keywords: techno-economic paradigm; regional development; Espírito Santo State.

JEL: O 33; O 18.

\section{Introdução}

O objetivo deste artigo é analisar a inserção do Espírito Santo no atual paradigma tecno econômico das tecnologias da informação e da comunicação (PTE das TICs) a partir de alguns indicadores de ciência, tecnologia e inovação (C,T\&I) do sistema produtivo capixaba, especialmente seu setor industrial. Essa análise se justifica para averiguar a capacidade inovativa da economia capixaba, inclusive porque a mesma tem apresentado indicadores de crescimento econômico acima da média nacional nas últimas décadas.

Como se sabe, este crescimento é puxado pela produção de commodities, como minério de ferro, celulose, aço, e, mais recentemente, petróleo e gás. A forte expansão nos últimos anos das grandes empresas produtoras de tais commodities, aliada às substanciais descobertas na área de petróleo e gás, permitem prever o crescimento da economia capixaba como sendo acima da 
média nacional pelos próximos anos. Mas ao mesmo tempo, surge no debate econômico local a preocupação em relação à necessária diversificação produtiva, preparando a economia capixaba para o futuro, inclusive porque a produção das referidas commodities apresenta problemas relacionados com o meio ambiente, ocupação do espaço urbano, e também com a finitude de algumas delas, como no caso do petróleo e gás.

Dadas as características do atual paradigma tecnoeconômico, considera-se que o processo de diversificação produtiva que a economia local deve passar nos próximos anos necessita da incorporação cada vez maior de conhecimento, inovações, etc. no que é produzido, visando manter ou ampliar a competitividade da economia capixaba. Porém, apesar do bom desempenho econômico das últimas décadas, o presente trabalho aponta que a economia capixaba apresenta uma inserção deficiente no que se refere ao atual paradigma das TICs, evidenciado pelo perfil produtivo, concentrado em produtos de baixo valor agregado e pouca intensidade tecnológica. Para comprovar isso, este estudo utiliza vários indicadores sobre inovação (com base na Pesquisa de Inovação Tecnológica - PINTEC) e desempenho econômico (neste caso, intensidade tecnológica das exportações), e também de algumas informações sobre as instituições capixabas de apoio a estas atividades.

No caso do Espírito Santo, os estudos mais abrangentes sobre aspectos inovativos na economia capixaba estão defasados - pelo menos em termos empíricos - como, por exemplo, Mota (1997) e Villaschi Filho (1999). Existem também alguns estudos setoriais, destacando seus respectivos aspectos inovativos como, por exemplo, os trabalhos de Nunes (2004), Santos Jr. (2005) e Vieira (2004), porém, sem um grau maior de sistematização que permita uma visão geral das atividades inovativas no estado.

Esses estudos, embora sejam importantes para se entender a realidade local, precisam de informações empíricas mais atuais e sistematizadas. Por isso, a contribuição do presente trabalho para as questões de C,T\&I da economia capixaba consiste em quatro pontos: 1) breve investigação sobre a performance capixaba na área de C\&T, a partir de dados sobre artigos científicos publicados e patentes depositadas - vale ressaltar que em todos os casos comparou-se os dados espírito-santenses com os dos outros doze estados mais desenvolvidos e com os da média nacional, para se ter uma ideia da real situação local em C,T\&I -; 2) a partir de dados regionais disponibilizados pela PINTEC (2005) - ver IBGE (2007) -, bem como por outros estudos empíricos, buscou-se analisar a inovação na indústria do Espírito Santo; 3) além disso, foram reunidas algumas evidências qualitativas sobre a atual situação da C,T\&I capixaba, principalmente sobre as instituições de apoio; e 4) foram avaliadas as exportações estaduais sob o ângulo da intensidade tecnológica de seu conteúdo baseando-se numa classificação fornecida pela OCDE (2003) e replicada para os dados nacionais pelo MDIC (2007b).

Conclui-se, a partir deste conjunto de informações, que, em comparação com a 
parcela do PIB que o Espírito Santo ocupa no contexto nacional, há um espaço significativo para o crescimento das atividades de C,T\&I na economia capixaba, evidenciando uma inserção deficiente desta economia no atual paradigma tecno-econômico, inclusive no que se refere ao papel das políticas públicas voltadas para estas atividades, que só recentemente passaram a contar com um arcabouço institucional mínimo de apoio governamental.

Para cumprir seu objetivo, o presente artigo é dividido em cinco seções. A primeira seção resenha alguns aspectos conceituais da relação entre inovação e concorrência, destacando a sua importância para a competitividade regional. A segunda seção apresenta um resumo da pesquisa empírica sobre inovação no Brasil, ressaltando aspectos gerais e da "geografia da inovação" da indústria nacional, focando o Espírito Santo. A terceira seção expõe dados da PINTEC (2005) e informações sobre as instituições locais de apoio às atividades científicas, tecnológicas e inovativas, demonstrando a inserção deficiente da economia capixaba no atual paradigma tecno econômico. Já a quarta seção apresenta evidências sobre as consequências de tal inserção deficiente, mostrando alguns dados de exportações sob a ótica da intensidade tecnológica. Finalmente, a quinta seção traz as considerações finais do trabalho.

\section{O PTE das TICs e o desenvolvimento regional: alguns elementos conceituais ${ }^{3}$}

Nas últimas décadas tem crescido de forma exponencial o debate sobre a inovação e seu papel no desenvolvimento econômico, resgatando as ideias seminais de Schumpeter (1911, 1934, 1943). Dessa forma, trabalhos como de Nelson \& Winter (1982), Dosi (1984, 1988), Lundvall (1992) e Freeman \& Soete (1997), dentre outros, analisam o papel da inovação no seio da atividade econômica.

Na teoria econômica existem pelo menos quatro visões de concorrência: a clássica, a marxista, a neoclássica e a schumpeteriana. Na teoria da Economia Industrial - ver, por exemplo, Kupfer \& Hasenclever (2002) - existem muitas formas ou dimensões da concorrência, sendo a por preços apenas a mais tradicional e mais simples, mas não a mais importante ou mais frequente. A concorrência ocorre também por diferenciação de produto e, notadamente, por inovações, que no sentido schumpeteriano envolvem quaisquer mudanças no "espaço econômico" no qual operam as empresas, sejam elas mudanças nos produtos, nos processos produtivos, nas fontes de matérias-primas, nas formas de organização produtiva, ou nos próprios mercados, inclusive em termos geográficos (Possas 2002).

Dessa forma, a característica mais importante da visão schumpeteriana é que a concorrência na economia capitalista é vista como um processo evolutivo,

${ }^{3}$ Grande parte desta seção foi baseada em Diniz (2001). 
e por isso dinâmico, gerado por fatores endógenos ao sistema econômico, especialmente as inovações que surgem da busca de novas oportunidades lucrativas por parte das empresas em sua interação competitiva (Possas 2002: 415). Assim é que a evolução dessa economia é vista ao longo do tempo como baseada num processo ininterrupto de introdução e difusão de inovações em sentido amplo.

Para entender melhor tal evolução da economia, os autores neo-schumpeterianos desenvolveram os conceitos de trajetórias tecnológicas (Nelson \& Winter 1977), paradigmas tecnológicos (Dosi 1982) e paradigmas tecno econômicos (Freeman \& Perez 1988). Como este último conceito é o mais abrangente para se entender a evolução econômica (La Rovere 2006: 290), ele será mais bem detalhado.

Paradigma tecnoeconômico foi definido por Freeman \& Perez (1988) como uma combinação de inovações de produto, de processo e técnicas, organizacionais e administrativas, que abrem um leque de oportunidades de investimento e de lucro. Os autores descreveram também as principais características dos sucessivos paradigmas tecnoeconômicos desde a $1^{\mathrm{a}}$ Revolução Industrial. No caso do atual paradigma - que começou por volta de 1980 -, a principal característica se refere às tecnologias de informação e comunicação; as indústrias-chave são as de computadores, produtos eletrônicos, software, telecomunicações, novos materiais e serviços de informação; o fator-chave é o microprocessador; e a principal forma de organização industrial e de competição é a rede de firmas.

Assim, Diniz (2001: 10) asseverou que:

em uma sociedade crescentemente dominada pelo conhecimento, as vantagens comparativas estáticas ou ricardianas, baseadas em recursos naturais, perdem importância e ganham destaque as vantagens construídas e criadas, cuja base está exatamente na capacidade diferenciada de gerar conhecimento e inovação. Em uma sociedade informacional se torna cada vez mais difícil para as empresas ou agentes produtivos reterem a exclusividade dos conhecimentos técnicos. A generalização desses os transforma em ubiqüidades, as quais destroem as vantagens comparativas diferenciadas e pré-estabelecidas e, portanto, a capacidade de competição. A manutenção dessas exige a criação de novas etapas do conhecimento e da capacitação, realimentando o processo inovativo.

Em função desses fatores e da crescente ampliação do conteúdo de conhecimento científico e tecnológico nos bens e serviços, países, regiões, localidades, empresas ou sociedades, são desafiados no sentido de se capacitarem científica e tecnologicamente com vistas a obterem sucesso produtivo e comercial. A esse respeito Porter (1990) afirmou que:

uma nova teoria deve partir da premissa de que a competição é dinâmica e evolui (...). Na competição real, o caráter essencial é a inovação e mudança (...). A vanta- 
gem competitiva é criada e mantida através de um processo altamente localizado. Diferenças nas estruturas econômicas, valores, culturas, instituições e histórias nacionais contribuem profundamente para o sucesso competitivo.

Ademais, consoante Lundvall \& Johnson (1994), a característica mais marcante do atual paradigma tecnoeconômico é o processo de aprendizado. Esse processo é fortemente localizado, em função da forma que interagem pesquisa, experiência prática e ação, através dos processos de aprender fazendo, usando, interagindo e aprendendo, que sintetizam a economia do aprendizado. Assim, a vantagem que um país, região ou localidade adquire está relacionada com sua capacidade de aprendizado e inovação (Porter 1990).

Nessa perspectiva, as regiões ou localidades se tornam pontos de criação de conhecimento e aprendizado. Florida (1995), por exemplo, diz que regiões devem adotar os princípios de criação de conhecimento e aprendizado contínuo, devendo se tornar "regiões que aprendem". Para que isso se concretize as regiões devem fornecer infraestruturas específicas que facilitem o fluxo de conhecimento, ideias e aprendizado, e que, ao mesmo tempo, tenham capacidade de governança local. Dado que o processo de inovação possui fortes componentes tácitos, cumulativos e localizados, os atributos regionais se tornam decisivos, daí surgindo a discussão do papel da inovação no desenvolvimento regional (Albagli 1999).

No entanto, a proximidade geográfica por si não é suficiente para assegurar o sucesso das experiências de geração de inovação e conhecimento. Por isso é que Diniz (2001: 13) afirmou que:

(...) além da importância da lógica cognitiva, as regiões possuem história, que têm seus pesos positivos ou negativos. Muitas vezes os atores locais não agem no sentido de se criarem interação e sinergia. Assim, as experiências de sucesso ou fracasso não podem ser generalizadas, uma vez que cada experiência é única e não reproduzível, uma vez que cada território é diferente do outro pelo seu conteúdo imaterial. Por outro lado, não se pode esperar que todas as regiões ou localidades gerem conhecimento de fronteira e se insiram na produção de bens de última geração tecnológica. Muitas regiões ou localidades continuarão especializadas na produção de bens tradicionais, inclusive de bens primários ou de serviços simples. No entanto, as mudanças tecnológicas contemporâneas penetram em todos os poros do sistema produtivo, afetando todos os setores ou atividades. Ainda que especializada em bens e serviços convencionais, sua produção eficiente está cada vez mais dependente das modernas tecnologias, através da inserção da informática em todos os setores, misturando o primário e o moderno.

Nessa linha, toda e qualquer localidade está inserida no contexto global de competição acirrada. Como mostraram Johnson \& Lundvall (2000), a economia do aprendizado não é necessariamente uma economia de alta tecnologia: ela é uma economia onde a habilidade para aprender é crucial para o sucesso econômico dos indivíduos, das firmas, de regiões e países, visto que apren- 
dizado se refere à construção de novas competências e estabelecimento de novas especializações, e não apenas ter acesso à informação.

Além disso, ocorre certa divisão setorial e/ou regional no processo de aprendizado, com algumas regiões e/ou setores no comando do processo de inovação, constituindo-se em regiões e/ou setores inovadores. Em contrapartida, outras regiões e/ou setores simplesmente adaptam e adotam os novos conhecimentos (Oinas \& Malecki 1999; Pavitt 1984).

Resumindo, a inovação é vista na ótica schumpeteriana como um fator crucial para ser competitivo - seja para empresas, seja para regiões - numa economia capitalista. Assim, uma peça fundamental para se inovar sob o atual PTE das TICs é o processo de aprendizado porque ele possibilita o acúmulo de conhecimento, essencial para a atividade de inovação. Portanto, assim como as empresas, as regiões têm que criar capacidade de aprendizado para seus agentes econômicos - famílias, empresas e setor público - a fim de inovarem e, consequentemente, de serem competitivas no atual estágio do desenvolvimento capitalista.

\section{Indicadores regionais de C\&T: o Espírito Santo no con- texto nacional}

A interação entre C\&T é tema bastante debatido na literatura sobre sistemas nacionais de inovação (Albuquerque et al. 2002). Nelson \& Rosenberg (1993: 6) apud Albuquerque et al. (2002: 227), por exemplo, resumiram essas interações - uma das características mais importantes dos sistemas de inovação -, destacando que a ciência tanto lidera como segue o progresso tecnológico.

Dessa forma, de um lado, Rosenberg (1982) salientou como os fatores econômicos determinam, em certa medida, o progresso da ciência, explicitando como o progresso tecnológico antecede e estimula o progresso científico. Por outro lado, Klevorick et al. (1995) pesquisaram como o progresso científico antecede e estimula o progresso tecnológico, apresentando dados empíricos sobre a função das universidades e da ciência como fonte de oportunidades tecnológicas para a inovação industrial. Portanto, para se ter um crescimento econômico sustentável a interação entre C\&T deve ocorrer sistematicamente (Albuquerque et al. 2002).

Outro fator importante para a interação entre C\&T no âmbito dos sistemas de inovação é a proximidade geográfica, discutida pelas literaturas sobre sistemas regionais de inovação e sobre spillovers de conhecimento. A título de ilustração, Jaffe (1989) apud Albuquerque et al. (2002: 228) destacou a importância da proximidade geográfica na relação entre universidades e firmas para a economia dos Estados Unidos.

Em relação ao Brasil, há estudos que indicam que o sistema de inovação 
brasileiro é incompleto e imaturo - Coutinho \& Ferraz (1994) já chamavam atenção para isso. Viotti et al. (2005), por exemplo, concluíram que, em termos internacionais, o Brasil está numa posição desfavorável. Isso porque a indústria brasileira apresenta uma taxa de inovação relativamente baixa quando comparada com alguns países europeus; ela apresentou também uma taxa de cooperação para o desenvolvimento de projetos de Pesquisa \& Desenvolvimento (P\&D) e outros de inovação comparativamente diminuta; o esforço para inovar das indústrias brasileiras é pequeno e os gastos são fortemente concentrados na compra de máquinas e equipamentos; por fim, as firmas que inovam no Brasil recebem pouco apoio do poder público, sobretudo em termos de financiamento.

Já Kannebley Jr. et al. (2004) disseram que o quadro geral da atividade inovativa na indústria nacional é de elevada assimetria. A razão disso é que a inovação é uma atividade positivamente relacionada com alguns poucos setores, com o tamanho da empresa - as grandes empresas têm uma taxa de inovação bem superior a das micro e pequenas empresas -, com o fato de exportaram ou não - as empresas que exportam inovam mais que as que não exportam -, e com a origem do capital - as indústrias de capital estrangeiro são mais inovadoras que as de capital nacional.

Com relação a esse último ponto, De Negri et al. (2005) apresentaram uma visão diferente, ou seja, a de que o esforço inovativo das empresas nacionais é maior que o das estrangeiras. Baseando-se em dados da PINTEC 2000, eles mostraram que $75,4 \%$ das firmas estrangeiras presentes no país não foram classificadas como firmas que inovam e diferenciam produtos e que os dispêndios das empresas nacionais com $\mathrm{P} \& \mathrm{D}$ foi de $\mathrm{R} \$ 2,03$ bilhões face $\mathrm{R} \$ 1,7$ bilhões das estrangeiras. Portanto, a análise de De Negri et al. (2005) relativiza as informações de Kannebley Jr. et al. (2004) sobre a defasagem da capacidade inovativa das firmas nacionais em relação às estrangeiras.

Outra característica do sistema de inovação brasileiro é sua disparidade regional. O trabalho de Cassiolato \& Lastres (1999) foi um dos primeiros a tentar captar as principais diferenças estaduais em termos de capacidade inovativa de arranjos produtivos dos principais estados brasileiros. Outro estudo interessante é o de Gonçalves (2007), que usa uma análise exploratória espacial dos dados de patentes depositadas no INPI, no período 1999-2001, como forma de descrever o padrão espacial da inovação no Brasil. Por meio dessa análise, a proposta do autor é confirmar a hipótese de existência, no Brasil, de um regime de polarização do tipo Norte-Sul, no que se refere às atividades tecnológicas.

Gonçalves (2007: 417) usou a seguinte tipologia, baseada no diagrama de dispersão de Moran para dados de patentes per capita para as microrregiões brasileiras, para descrever os agrupamentos espaciais inovativos do país: padrão AA (Alto-Alto) para regiões de alta atividade tecnológica e inovadora e com altos níveis de transbordamento tecnológico espacial; padrão AB (Alto- 
Baixo) para regiões de alta atividade tecnológica e inovadora, mas com baixos níveis de transbordamento tecnológico espacial; padrão BA (Baixo-Alto) para regiões de baixa atividade tecnológica e inovadora, mas com altos níveis de transbordamento tecnológico espacial por estarem próximas a regiões do tipo AA; padrão BB (Baixo-Baixo) para regiões de baixa atividade tecnológica e inovadora e com baixos níveis de transbordamento tecnológico espacial.

O principal resultado encontrado por Gonçalves (2007) é que os regimes espaciais de inovação no Brasil apresentam tendências de agrupamento espacial. As Regiões Norte, Nordeste e grande parte do Centro-Oeste apresentam uma homogeneidade em termos de baixa atividade tecnológica, o que, segundo o autor, confirma a existência no país do fenômeno de polarização NorteSul. Já as regiões Sudeste e Sul apresentam maior quantitativo de padrões espaciais de inovação. Os padrões AA estão, em sua maior parte, no estado de São Paulo.

Além de São Paulo, Minas Gerais se destaca no Sudeste, apesar desta região aparecer como um grande espaço vazio em termos tecnológicos. As suas exceções são as microrregiões vizinhas ao estado de São Paulo e Belo Horizonte, que aparece como padrão AB, juntamente com Ipatinga. As ausências no Sudeste são as microrregiões do estado do Rio de Janeiro e do Espírito Santo.

No Sul do país existem aglomerações espaciais do tipo AA em todos os seus estados. No Paraná se destacam as microrregiões de Curitiba, Ponta Grossa e Cascavel, no oeste. Em Santa Catarina três microrregiões se destacam: uma perto do litoral do Estado, composta por Joinvile, Blumenau, Itajaí, São Bento do Sul e Rio do Sul, e outra mais a oeste do estado, formada por Xanxerê, Concórdia e Joaçaba; a terceira é a de Florianópolis, Tubarão e Criciúma, também no litoral catarinense. Por fim, no Rio Grande do Sul duas aglomerações são as mais importantes: a primeira e principal é o corredor formado por Porto Alegre, Gramado-Canela, Montenegro, Caxias do Sul, Guaporé, Passo Fundo e Não-Me-Toque; a outra aglomeração é formada por Santa Cruz do Sul e Cachoeira do Sul.

Essas informações levaram Gonçalves (2007) a concluir que a atividade tecnológica brasileira, quando medida por patentes per capita, restringe-se a um polígono ainda mais restrito e descontínuo que a notória área poligonal das “aglomerações industriais relevantes" de Diniz \& Crocco (1996), considerandose apenas as microrregiões do tipo AA. Além destas áreas, existem algumas "ilhas tecnológicas" (regiões do tipo $\mathrm{AB}$ ), sendo a principal a microrregião de Belo Horizonte.

Por fim, deve-se ressaltar que o estudo de Albuquerque et al. (2002) com base em estatísticas de artigos científicos, patentes e pesquisadores permitiu uma caracterização mais precisa das diferenças regionais de C\&T no país. Com base nas ideias de Albuquerque et al. (2002) foi elaborada a Tabela 1, que mostra alguns dados recentes sobre as diferenças regionais em termos 
de C\&T. Em linhas gerais, os dados da referida tabela ratificam o principal resultado encontrado por aqueles autores, qual seja, a distribuição espacial das atividades científicas e tecnológicas do Brasil está concentrada no Centro-Sul do país, sobretudo nos estados que compõem a região do polígono. E assim como em Albuquerque et al. (2002), os dados continuam evidenciando que esta concentração é superior à da atividade econômica.

Para se ter uma ideia mais precisa dessa concentração, totalizaram-se os dados dos estados do polígono (SP, MG, PR, SC e RS) na Tabela 1. Esta região concentrou 89,6\% das patentes concedidas no país (2004), 63,6\% dos artigos científicos (2001-2003), 60,4\% dos pesquisadores (2004) e 58,5\% do PIB (2004). Quanto às demais regiões, notadamente as Regiões Norte e CentroOeste, as estatísticas confirmam a tese de Diniz \& Gonçalves (2001) de "vazio e estagnação" em relação ao seu potencial para gerar atividade produtiva intensiva em conhecimento.

No que tange ao Espírito Santo, a Tabela 1 indica que o estado apresentou um desempenho discreto na área de C\&T, embora esteja geograficamente localizado na Região Centro-Sul do país. Ele representou apenas 0,4\% das patentes concedidas, 0,7\% dos artigos científicos, 0,9\% dos pesquisadores, gerando 2,0\% do PIB nacional ${ }^{4}$. Tais dados são um indicativo de que a inserção capixaba no contexto regional brasileiro é pouco dinâmica do ponto de vista científico e tecnológico, o que fica ainda mais claro se for considerado que os estados do polígono, com exceção de Minas Gerais, apresentam participação no indicador de patentes ainda maior do que a do PIB no contexto da economia brasileira. Vale lembrar que a partir de 2005 emergiu um novo sistema estadual de C\&T, como será visto mais à frente, mas ainda é cedo para avaliar seu impacto na economia local.

\footnotetext{
${ }^{4}$ Duas informações são importantes no sentido de se relativizar esses dados sobre patentes no Espírito Santo: de um lado, os dados sobre patentes depositadas nos Estados Unidos provavelmente mostrariam que a participação capixaba no total nacional é menor ainda que nas patentes depositadas no INPI, como sugerem os dados de Albuquerque et al. (2002); por outro lado, as atividades inovativas podem estar sub-dimensionadas no estado pelo fato do principal produtor local de inovações, o Instituto Capixaba de Pesquisa e Extensão Rural (INCAPER), não registrar grande parte das mesmas sob a forma de patente.
} 

TABELA 1 - PARTICIPAÇÃO DAS GRANDES REGIÕES E ESTADOS
NO TOTAL NACIONAL DE PATENTES*, ARTIGOS CIENTÍFICOS**,
PESQUISADORES*** e PIB

em percentual (\%)

\begin{tabular}{|c|c|c|c|c|}
\hline $\begin{array}{l}\text { Grandes Regiões e } \\
\text { estados selecionados }\end{array}$ & $\begin{array}{c}\text { Artigos científicos } \\
(2001-2003)\end{array}$ & $\begin{array}{c}\text { Pesquisadores } \\
(2004)\end{array}$ & $\begin{array}{c}\text { Patentes } \\
(\mathbf{2 0 0 4 )}\end{array}$ & $\begin{array}{c}\text { PIB } \\
(\mathbf{2 0 0 4})\end{array}$ \\
\hline Região Norte & 2,84 & 3,29 & 0,92 & 5,30 \\
\hline Amazonas & 0,96 & 1,21 & 0,75 & 2,00 \\
\hline Pará & 1,27 & 1,36 & 0,05 & 1,90 \\
\hline Região Nordeste & 13,63 & 14,29 & 3,58 & 14,10 \\
\hline Bahia & 3,07 & 3,35 & 0,35 & 4,90 \\
\hline Ceará & 2,11 & 2,24 & 2,21 & 1,90 \\
\hline Pernambuco & 3,17 & 3,36 & 0,70 & 2,70 \\
\hline Região Centro-Oeste & 6,09 & 7,00 & 0,95 & 7,50 \\
\hline Goiás & 1,72 & 1,80 & 0,47 & 2,30 \\
\hline Região Sudeste & 55,24 & 55,69 & 61,68 & 54,90 \\
\hline Espírito Santo & 0,74 & 0,90 & 0,40 & 2,00 \\
\hline Minas Gerais & 10,17 & 9,24 & 6,99 & 9,40 \\
\hline Rio de Janeiro & 13,12 & 14,09 & 4,60 & 12,60 \\
\hline São Paulo & 31,21 & 31,46 & 49,69 & 30,90 \\
\hline Região Sul & 22,20 & 19,73 & $\mathbf{3 2 , 8 7}$ & 18,20 \\
\hline Paraná & 7,25 & 6,79 & 10,82 & 6,10 \\
\hline Rio Grande do Sul & 10,32 & 8,78 & 15,43 & 8,10 \\
\hline Santa Catarina & 4,63 & 4,16 & 6,62 & 4,00 \\
\hline Estados do polígono & 63,59 & 60,43 & 89,55 & 58,50 \\
\hline Brasil & 100,00 & 100,00 & 100,00 & 100,00 \\
\hline
\end{tabular}




\section{O Espírito Santo no atual paradigma: uma inserção deficiente}

No caso do Espírito Santo, os estudos mais abrangentes sobre aspectos inovativos estão defasados em termos empíricos, como por exemplo, Mota (1997) e Villaschi Filho (1999). Existem também alguns estudos setoriais, destacando seus respectivos aspectos inovativos como, por exemplo, os trabalhos de Nunes (2004), Santos Jr. (2005) e Vieira (2004), porém, sem um grau maior de sistematização que permita uma visão geral das atividades inovativas no Estado.

Esses estudos, especialmente Villaschi Filho (1999), apontavam que o desempenho inovativo da economia capixaba era modesto no final dos anos 1990. Os dados da seção 2 deste trabalho confirmam esta impressão para a situação atual da economia capixaba, mas são necessários mais estudos para se refinar tal conclusão. O objetivo desta seção é contribuir neste sentido, a partir de dados da PINTEC e de algumas evidências qualitativas obtidas por meio de entrevistas junto a atores importantes do Sistema Capixaba de Inovação (SCI) 5 .

\subsection{A realidade atual da inovação no Espírito Santo: o que mostram os dados da PINTEC (2005)? ${ }^{6}$}

\subsubsection{Dados gerais}

Durante o período 2003-2005, a PINTEC teve uma amostra de mais de 91 mil empresas do setor industrial do Brasil, segundo a Tabela 2. Deste total, cerca de 30,3 mil ou 33,4\% implementaram algum tipo de inovação - este percentual significa a taxa de inovação da indústria.

Dentre os estados pesquisados, Amazonas apresentou a maior taxa de inovação, 50,6\% (Tabela 2). Os destaques negativos nesse período foram Bahia, Ceará, Minas Gerais, Rio de Janeiro e Goiás, pois apresentaram taxas de inovação abaixo da média brasileira de 33,4\%. Em termos absolutos, porém, São Paulo continuou com o maior quantitativo de empresas industriais inovadoras do Brasil, seguido por Rio Grande do Sul, Minas Gerais, Paraná e Santa Catarina, respectivamente. Estes estados, por sua vez, concentravam 75,5\% das empresas industriais inovadoras do país, o que reafirma as ideias de Diniz (2002) e Domingues \& Ruiz (2006a) de que esses cinco estados concentram o eixo de desenvolvimento industrial e tecnológico do país.

\footnotetext{
${ }^{5}$ Expressão cunhada por Villaschi Filho (1999).

${ }^{6} \mathrm{O}$ presente trabalho levou em conta somente os dados da PINTEC (2005), deixando de fora os dados das pesquisas de 2000 e 2003, porque seu objetivo é analisar as estatísticas mais recentes sobre inovação das empresas industriais capixabas e dos demais estados abrangidos pela pesquisa, e não a sua evolução.
} 
A indústria do Espírito Santo, apesar de ser relativamente tardia, apresentou taxas de inovação acima da média brasileira no período 2003-2005. Neste período, a taxa de inovação da indústria capixaba permaneceu relativamente alta, $37,7 \%$, a $3^{\text {a }}$ maior do país - essa estatística, porém, será relativizada a seguir com a apresentação de outros indicadores. Por fim, o percentual de empresas industriais inovadoras capixabas em relação ao total do país atingiu $2,4 \%$.

\section{TABELA 2 - EMPRESAS INDUSTRIAIS QUE IMPLEMENTARAM INOVAÇÃO, SEGUNDO UNIDADES DA FEDERAÇÃO (2003-2005)}

\begin{tabular}{l|c|c|c|c}
\hline $\begin{array}{l}\text { Unidades da } \\
\text { Federação }\end{array}$ & Total (1) & $\begin{array}{l}\text { Empresas que } \\
\text { inovaram (2) }\end{array}$ & $\begin{array}{c}\text { Taxa de } \\
\text { inovação(3) }\end{array}$ & $\begin{array}{c}\text { Part. relativa } \\
\text { (4) }\end{array}$ \\
\hline Amazonas & 585 & 296 & 50,6 & 1,0 \\
\hline Pará & 1.292 & 440 & 34,0 & 1,4 \\
\hline Bahia & 2.201 & 633 & 28,8 & 2,1 \\
\hline Ceará & 2.000 & 521 & 26,1 & 1,7 \\
\hline Pemambuco & 1.878 & 692 & 36,8 & 2.3 \\
\hline Espírito Santo & 1.969 & 742 & 37.7 & 2.4 \\
\hline Minas Gerais & 10.861 & 3.203 & 29.5 & 10.5 \\
\hline Riode Janeiro & 5.294 & 1.362 & 25.7 & 4.5 \\
\hline São Paulo & 31.990 & 10.734 & 33,6 & 35,3 \\
\hline Paraná & 7.792 & 3.154 & 40.5 & 10.4 \\
\hline Rio Grande do Sul & 8.840 & 3.225 & 36.5 & 10,6 \\
\hline Santa Catarina & 7.585 & 2.648 & 34,9 & 8,7 \\
\hline Goiás & 2.398 & 642 & 26,8 & 2,1 \\
\hline Sub-total & $\mathbf{8 4 . 6 8 5}$ & $\mathbf{2 8 . 2 9 2}$ & $\mathbf{3 3 , 4}$ & $\mathbf{9 3 , 1}$ \\
\hline Demais estados & $\mathbf{6 . 3 7 0}$ & $\mathbf{2 . 0 8 5}$ & $\mathbf{3 2 , 7}$ & $\mathbf{6 , 9}$ \\
\hline Estados do polígono & $\mathbf{6 7 . 0 6 8}$ & $\mathbf{2 2 . 9 6 4}$ & $\mathbf{3 4 . 3}$ & $\mathbf{7 5 , 6}$ \\
\hline Brasil & $\mathbf{9 1 . 0 5 5}$ & $\mathbf{3 0 . 3 7 7}$ & $\mathbf{3 3 , 4}$ & $\mathbf{1 0 0 , 0}$ \\
\hline
\end{tabular}

Fonte: IBGE $(20 \%)$.

(1) Total de empresas industriais pesquisada s.

(2) Total de em presas industriais que implementara m ino vações de produto e/ou process o.

(3) Percentual relativo de empres as ind ustriais que implementa ram inovações: (2)/(1) $=(3)$.

(4) Percentual relativo ao total de empresas industriais pesquis adas no Bras il. 


\subsection{2) Esforço empreendido para inovar}

A Tabela 3 mostra que das empresas industriais brasileiras que implementaram inovações entre os anos de 2003 e de 2005, 81,3\% o fizeram por meio de aquisição de máquinas e equipamentos. A segunda atividade inovativa mais utilizada foi o treinamento (59,2\%), seguida de projetos industrias $(39,4 \%)$. As atividades internas de $\mathrm{P} \& \mathrm{D}$, no entanto, foram empregadas por apenas 19,9\% das firmas industriais que inovaram no período.

Esses dados comprovam a tese de que em países em desenvolvimento as inovações se dão muito mais pela compra - importação de outros países em alguns casos - de máquinas e equipamentos tecnologicamente mais avançados. A atividade de P\&D, tida como uma das mais importantes fontes de inovação para autores como Freeman \& Soete (1997), é realizada, proporcionalmente, por poucas empresas industriais no Brasil.

Nas estruturas produtivas dos estados essa tendência não é muito diferente, sendo em alguns casos até exacerbada. Em estados como Amazonas, Pará e Espírito Santo, a aquisição de máquinas e equipamentos foi feita por mais de $92,1 \%$ de suas empresas industriais pesquisadas, percentual bem superior à média verificada para o país. No caso das atividades internas de $\mathrm{P} \& \mathrm{D}, \mathrm{a}$ situação é ainda pior: Pará, Pernambuco e Espírito Santo apresentaram percentuais bem abaixo da média nacional. Além disso, em todas as atividades inovativas existe uma concentração muito grande nos estados mais desenvolvidos (SP, MG, PR, RS e SC) - acima de 74,8\% das firmas inovadoras do país em todos os casos.

TABELA 3 - EMPRESAS QUE IMPLEMENTARAM INOVAÇÕES, SEGUNDO ATIVIDADES INOVATIVAS DESENVOLVIDAS E UNIDADES DA FEDERAÇÃO (2003-2005)

\begin{tabular}{|c|c|c|c|c|c|c|c|c|c|c|c|c|}
\hline \multirow[t]{2}{*}{$\begin{array}{l}\text { Unidades da } \\
\text { Federação }\end{array}$} & \multicolumn{2}{|c|}{$\begin{array}{l}\text { Ativ. } \\
\text { interna de } \\
\text { P\&D }\end{array}$} & \multicolumn{2}{|c|}{$\begin{array}{c}\text { Aquisição } \\
\text { de } \\
\text { softuvare }\end{array}$} & \multicolumn{2}{|c|}{$\begin{array}{c}\text { Aquisição } \\
\text { de } \\
\text { máq. e } \\
\text { equip. }\end{array}$} & \multicolumn{2}{|c|}{ Treinamento } & \multicolumn{2}{|c|}{$\begin{array}{l}\text { Introd. das } \\
\text { inovações } \\
\text { tecnológicas } \\
\text { no mercado }\end{array}$} & \multicolumn{2}{|c|}{$\begin{array}{c}\text { Proj. } \\
\text { industrial e } \\
\text { outras prep. } \\
\text { técnicas }\end{array}$} \\
\hline & $\mathbf{1}$ & 2 & $\mathbf{1}$ & 2 & $\mathbf{1}$ & 2 & $\mathbf{1}$ & 2 & $\mathbf{1}$ & 2 & $\mathbf{1}$ & 2 \\
\hline Amazonas & 21,3 & 1,0 & 18,6 & 1,3 & 92,7 & 1,1 & 73,8 & 1,2 & 21,9 & 0,8 & 28,6 & 0,7 \\
\hline Pará & 5.5 & 0,4 & 3,0 & 0,3 & 98,0 & 1,7 & 63,5 & 1,6 & 12,1 & 0,6 & 41,3 & 1,5 \\
\hline Bahia & 19,8 & 2,1 & 17,1 & 2,6 & 85,4 & 2,2 & 67,4 & 2,4 & 27,4 & 2,0 & 52,8 & 2,8 \\
\hline Ceará & 27,9 & 2,4 & 18,4 & 2,3 & 84,0 & 1,8 & 54,2 & 1,6 & 33,1 & 2,0 & 32,0 & 1,4 \\
\hline Pernambuco & 8,7 & 1,0 & 10,6 & 1,7 & 83,8 & 2,3 & 51,6 & 2,0 & 15,7 & 1,3 & 43,1 & 2,5 \\
\hline Espírito Santo & 3,8 & 0,5 & 8,3 & 1,4 & 92,1 & 2,8 & 48,9 & 2,0 & 17,7 & 1,5 & 31,4 & 1,9 \\
\hline Minas Gerais & 13,6 & 7,2 & 11,4 & 8,6 & 84,0 & 10,9 & 55,6 & 9,9 & 23,1 & 8,7 & 36,3 & 9,7 \\
\hline Rio de Janeiro & 27,6 & 6,2 & 17,7 & 5,7 & 73,5 & 4,1 & 50,9 & 3,9 & 26,8 & 4,3 & 37,1 & 4,2 \\
\hline São Paulo & 27,6 & 48,9 & 16,9 & 42,7 & 77,9 & 33,8 & 59,2 & 35,4 & 32,6 & 41,0 & 43,3 & 38,8 \\
\hline Paraná & 17,2 & 9,0 & 13,5 & 10,0 & 86,2 & 11,0 & 62,3 & 10,9 & 30,4 & 11,2 & 35,3 & 9,3 \\
\hline $\begin{array}{l}\text { Rio Grande do } \\
\text { Sul }\end{array}$ & 19,7 & 10,5 & 14,6 & 11,1 & 75,5 & 9,9 & 63,5 & 11,4 & 32,9 & 12,4 & 47,8 & 12,9 \\
\hline Santa Catarina & 16,0 & 7,0 & 10,6 & 6,6 & 86,2 & 9,2 & 60,7 & 8,9 & 26,7 & 8,3 & 37,6 & 8,3 \\
\hline Goiás & 10,8 & 1,1 & 14,0 & 2,1 & 81,9 & 2,1 & 53,8 & 1,9 & 17,3 & 1,3 & 27,0 & 1,4 \\
\hline $\begin{array}{l}\text { Estados do } \\
\text { polígono }\end{array}$ & 21,8 & 82,6 & 14,6 & 79,0 & 80,5 & 74,8 & 59,9 & 76,5 & 30,4 & $\mathbf{8 1 , 5}$ & 41,2 & 79,0 \\
\hline Brasil & 19,9 & 100,0 & 14,0 & 100,0 & 81,3 & 100,0 & 59,2 & 100,0 & 28,2 & 100,0 & 39,4 & 100,0 \\
\hline
\end{tabular}

Fonte: IBGE (2007).

*Nota: considerou-se apenas as empresas que concederam grau de importância alto e médio às atividades inovativas

desenvolvidas.

(1) Percentual relativo ao total de empresas que implementaram inovações.

(2) Percentual relativo ao total de empresas qu e implementaram inovações no Brasil. 
A Tabela 4 complementa e ao mesmo tempo ratifica as informações da Tabela 3. De uma forma geral, tal tabela mostra que $21,9 \%$ das empresas industriais brasileiras que inovaram realizaram algum dispêndio para isso, o que totalizou $2,8 \%$ da receita líquida de vendas destas empresas. Coerente com a tabela anterior, 78,6\% das firmas que tiveram dispêndio com inovação foi para a aquisição de máquinas e equipamentos, o que significou 48,4\% de seus gastos com atividades inovativas. Em seguida vêm os projetos industriais, a introdução de inovações tecnológicas e o treinamento. Os gastos com P\&D foram feitos por 25,3\% das empresas que investiram em inovação, o que representou $20,7 \%$ de suas receitas - o $2^{\circ}$ maior gasto com inovação das firmas industriais.

No caso do Espírito Santo, 25,2\% de suas empresas industriais que inovaram realizaram algum dispêndio com esta atividade, o que representou 2,9\% da receita destas empresas. Tais percentuais são superiores à média nacional, mas a análise segundo as atividades inovativas revela que 90,0\% das firmas que investiram em inovação o fizeram na aquisição de máquinas e equipamentos - o maior percentual do país entre os estados selecionados - e somente $3,8 \%$ o fizeram com atividades internas de P\&D - o menor percentual do país entre os estados.

\section{TABELA 4 - DISPÊNDIOS RELACIONADOS ÀS ATIVIDADES INOVATIVAS DESENVOLVIDAS, SEGUNDO UNIDADES DA FEDERAÇÃO (2005)}

\begin{tabular}{|c|c|c|c|c|c|c|c|c|c|c|c|c|c|c|}
\hline \multirow[t]{2}{*}{$\begin{array}{l}\text { Unidades } \\
\text { da } \\
\text { Federação }\end{array}$} & \multicolumn{2}{|c|}{ Total } & \multicolumn{2}{|c|}{$\begin{array}{c}\text { Ativ. } \\
\text { internas } \\
\text { de } \\
\text { P\&D }\end{array}$} & \multicolumn{2}{|c|}{$\begin{array}{c}\text { Aquisição } \\
\text { de } \\
\text { software }\end{array}$} & \multicolumn{2}{|c|}{$\begin{array}{l}\text { Aquisição } \\
\text { de máq.e } \\
\text { equip. }\end{array}$} & \multicolumn{2}{|c|}{$\begin{array}{l}\text { Treina- } \\
\text { mento }\end{array}$} & \multicolumn{2}{|c|}{$\begin{array}{c}\text { Introd. das } \\
\text { inovações } \\
\text { no } \\
\text { mercado }\end{array}$} & \multicolumn{2}{|c|}{$\begin{array}{c}\text { Proj. } \\
\text { industrial }\end{array}$} \\
\hline & $\mathbf{1}$ & & $\mathbf{1}$ & 3 & 1 & 3 & $\mathbf{1}$ & 3 & $\mathbf{1}$ & 3 & $\mathbf{1}$ & 3 & $\mathbf{1}$ & 3 \\
\hline Ama & 5,5 & 2,6 & 4,5 & 20,9 & 4,3 & 2,6 & 83,3 & 54,4 & 42,1 & 3,4 & 22,1 & 13,9 & 31,6 & 8,2 \\
\hline Pará & 9 & 1,8 & 9 & 2,3 & 3,2 & 0,5 & 87,2 & 57,9 & 13,2 & 4,6 & 4,4 & & 4,0 & 33,1 \\
\hline Bahia & 1,7 & 1,3 & 22,9 & 18,6 & 27,0 & 1,4 & 88,0 & 59,2 & 41,9 & 1,5 & 30,1 & 3,2 & 30,1 & 8,0 \\
\hline Ceará & 4,8 & 2,3 & 29,4 & 12,6 & 28,7 & 1,6 & 71,4 & 39,8 & 23,3 & 1,9 & 39,4 & 13,7 & 36,1 & 17,2 \\
\hline Pernan & 6,7 & 1,6 & 9,6 & 6,9 & 13,7 & 2,6 & 74,3 & 75,0 & 14,0 & 14 & 9,5 & 5,1 & 33,9 & 74 \\
\hline $\begin{array}{l}\text { Espírito } \\
\text { Santo }\end{array}$ & 5,2 & 2 & 3,8 & 4,7 & 3,9 & 5 , & scto & 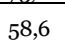 & 6,9 & 2,4 & 14,0 & 1,8 & 17,4 & 19,4 \\
\hline Minas Gerais & 16,3 & 0 & 9,4 & 14,8 & 15,9 & 1,4 & 83,0 & 53,0 & 25,7 & 7 & 27,2 & 3,8 & 33,4 & 17,5 \\
\hline & 5,4 & 1,5 & 30,3 & 39,9 & 17,8 & 0,7 & 76,9 & 24,1 & 26,8 & 1,0 & 31,8 & 3,3 & 46,2 & 25,0 \\
\hline São Paulo & 23,9 & 3,5 & 33,6 & 21,5 & 20,5 & 1,8 & 74,1 & 48,2 & 27,9 & 1,9 & 34,0 & 8,2 & 39,6 & 10,6 \\
\hline Paraná & 23,2 & & 26,8 & 13,9 & 22,3 & 5 & 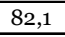 & $56-1$ & 29,1 & 8 & 32,3 & 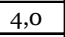 & 33,4 & 10,2 \\
\hline $\begin{array}{l}\text { Rio Grande } \\
\text { do Sul }\end{array}$ & 24,4 & 2,2 & 5,0 & 18 & 18,2 & 1,5 & 71,9 & 53,0 & 26,1 & $t$ & | & 7,0 & 35,8 & . \\
\hline $\begin{array}{l}\text { Santa } \\
\text { Catarina }\end{array}$ & 22,0 & 2,0 & 21,2 & 22,5 & 15,3 & 1,7 & 86,1 & 59,3 & 28,9 & 1,3 & 27,8 & 4,6 & 27,6 & 8,5 \\
\hline Goiás & 20,1 & 2,9 & 9,2 & 5,5 & 16,2 & 0,6 & 81,5 & 71,4 & 16,9 & 1,8 & 21,9 & 7,0 & 18,2 & 11,0 \\
\hline Brasil & 21,9 & 2,8 & 25,3 & $\mathbf{2 0}, 7$ & 17,9 & 2,0 & 78,6 & 48,4 & 26,1 & $\mathbf{1 , 8}$ & 29,5 & 6,8 & 34,3 & 12,9 \\
\hline
\end{tabular}

Fonte: IBGE (2007).

(1) Percentual de empresas que realizam dispên dios em atividades in ovativas (por tipos) em relação ao total de empresas que inovaram.

(2) Percentual de dispêndios das ativida des in ovativas em relação à receita líquida de vendas das empresas.

(3) Percentual relativo ao total de dispên dios com atividades inovativas. 
Neste trabalho, insiste-se na realização de P\&D pelas firmas porque assim o aprendizado poderá ser maior. Se uma firma realiza este tipo de esforço tecnológico ela aumenta a sua capacidade de "identificar, assimilar e explorar a informação ou conhecimento já existente no ambiente" (Cohen \& Levintahl 1989). É criada uma "capacidade de absorção ou de aprendizado" que difere do learning-by-doing, pois neste a firma torna-se mais experiente e mais eficiente em executar algo que já faz, enquanto naquele o conhecimento externo adquirido a capacita fazer algo completamente diferente (Gonçalves et al. 2005).

Nessa perspectiva, o trabalho de Simões et al. (2005) traz informações sobre gastos em P\&D nas indústrias dos estados. Segundo eles, a concentração dos gastos das atividades inovativas internas às firmas em São Paulo é expressiva. Dos 23 setores considerados, ele exerce a liderança em 19, concentrando 57\% das inovações realizadas no país. Os quatro setores restantes são liderados pelo Rio Grande do Sul (fumo e couro), Minas Gerais (extrativismo) e Santa Catarina (vestuário e acessórios).

Os dados revelaram que os estados da Região Sul têm um importante papel no quadro nacional de distribuição da capacidade de investimento e introdução de novidades no mercado. A união dos esforços inovativos do Rio Grande do Sul, de Santa Catarina e do Paraná supera em muito a junção dos gastos realizados no Sudeste, excluindo São Paulo: 24,78\% contra 14,14\% respectivamente. Os demais estados das regiões Norte, Nordeste, Centro-Oeste e o Espírito Santo, têm uma pequena participação nos gastos em P\&D do Brasil. Juntos, Amazonas, Pará, Ceará, Pernambuco, Bahia e Espírito Santo representam somente $2,24 \%$ dos gastos em P\&D do país.

\subsection{3) Relações de cooperação}

Outro fator apontado como importante para a realização de inovações é a relação de cooperação empregada para tal. A Tabela 5 mostra que a taxa de cooperação é muito baixa na indústria brasileira, pois somente $7,2 \%$ das firmas industriais que realizaram alguma inovação cooperaram com outras organizações para tal fim. Dessas que cooperaram, $61,5 \%$ o fez com seus fornecedores, 59,2\% com seus clientes ou consumidores e 31,4\% com universidades e instituições de pesquisa. As organizações menos usadas para a cooperação foram os centros de capacitação profissional e as empresas de consultoria. 
TABELA 5 - RELAÇÕES DE COOPERAÇÃO DAS EMPRESAS QUE INOVARAM, SEGUNDO UNIDADES DA FEDERAÇÃO (2003-2005)

\begin{tabular}{|c|c|c|c|c|c|c|c|}
\hline $\begin{array}{l}\text { Unidades da } \\
\text { Federação }\end{array}$ & Total & $\begin{array}{c}\text { Taxa de } \\
\text { cooperação } \\
\text { (\%) }\end{array}$ & $\begin{array}{c}\text { Clientes ou } \\
\text { consumidores } \\
\text { (\%) }\end{array}$ & $\begin{array}{c}\text { Fornecedores } \\
\text { (\%) }\end{array}$ & $\begin{array}{c}\text { Consultoria } \\
\text { (\%) }\end{array}$ & \begin{tabular}{|c|} 
Universidades \\
e inst. de \\
pesquisa (\%)
\end{tabular} & $\begin{array}{c}\text { Centros de } \\
\text { capacitação } \\
\text { profissional } \\
(\%)\end{array}$ \\
\hline Amazonas & 40 & 13,7 & 34,4 & 78,3 & 18,6 & 22,2 & 20,5 \\
\hline Pará & 37 & 8,4 & 82,7 & 8,7 & 11,4 & 94,6 & 83,3 \\
\hline Bahia & 69 & 10,9 & 76,7 & 78,1 & 10,6 & 14,7 & 18,1 \\
\hline Ceará & 20 & 3,8 & 53,7 & 63,0 & 15,3 & 21,9 & 17,1 \\
\hline Pernambuco & 16 & 2,3 & 32,2 & 38,6 & 32,0 & 53,3 & 21,8 \\
\hline Espírito Santo & 50 & 6,7 & 80,6 & 100,0 & 5,9 & 9,8 & 74,7 \\
\hline Minas Gerais & 112 & 3,5 & 51,2 & 70,0 & 35,5 & 50,6 & 18,2 \\
\hline Rio de Janeiro & 166 & 12,2 & 31,6 & 44,5 & 12,0 & 27,9 & 34,7 \\
\hline São Paulo & 933 & 8,7 & 59,8 & 63,8 & 20,7 & 25,0 & 18,3 \\
\hline Paraná & 259 & 8,2 & 71,3 & 55,2 & 41,0 & 40,9 & 25,4 \\
\hline Rio Grande do Sul & 309 & 9,6 & 67,2 & 57,3 & 25,1 & 33,8 & 17,3 \\
\hline Santa Catarina & 107 & 4,0 & 51,9 & 77,7 & 17,1 & 39,7 & 22,2 \\
\hline Goiás & 14 & 2,1 & 29,7 & 67,3 & 14,6 & 47,2 & 14,6 \\
\hline $\begin{array}{l}\text { Estados do } \\
\text { polígono }\end{array}$ & 1.720 & 7,5 & 61,8 & 62,6 & 25,3 & 31,6 & 19,4 \\
\hline Brasil & 2.194 & 7,2 & 59,2 & 61,5 & 22,6 & 31,4 & 23,1 \\
\hline
\end{tabular}

Fon te: IBGE (2007)

Nota: considerou-se apenas as empresas que concederam grau de importância alto e médio às parcerias de cooperação para inovar.

Do ponto de vista regional, os dados evidenciam mais uma predominância dos estados mais desenvolvidos - aqueles que pertencem à região do polígono -, concentrando 78,4\% das firmas do país que cooperaram para inovar.

Em relação ao Espírito Santo, ele apresentou uma taxa de cooperação pouco abaixo da média nacional $(6,7 \%)$. Contudo, $100,0 \%$ delas cooperaram com seus fornecedores, $80,6 \%$ com clientes e 74,7\% com centros de capacitação, percentuais bem acima da média do país. O destaque negativo no estado foi a baixa cooperação com universidades e institutos de pesquisa $(9,8 \%)$.

Em suma, todos esses dados da PINTEC (2005) sobre atividades inovativas mostram que a indústria do Espírito Santo, embora a princípio apresente uma taxa de inovação relativamente substancial, tem na verdade uma capacidade inovativa interna às firmas limitada. Isso porque parte expressiva de suas inovações se dá por meio de compra de máquinas e equipamentos, completando o quadro um baixo nível de empresas que realizaram P\&D e cooperação, notadamente com as universidades.

\section{2) Instituições de apoio ${ }^{7}$}

No que se refere às instituições de apoio à pesquisa e à inovação, somente muito recentemente o Espírito Santo passou a ter um arcabouço mínimo para o apoio ao desenvolvimento destas atividades (Mota 2007). A FAPES e a Secretaria de Estado de Ciência e Tecnologia (SECT) surgiram em 2004, começando a funcionar plenamente em 2005, e o Núcleo de Inovação Tecnológica do Espírito Santo (NITES) foi criado em 2007.

\footnotetext{
${ }^{7}$ Esta seção é baseada em Grassi et al. (2008).
} 
Porém, nota-se que os esforços referentes à área de C\&T, apesar de substanciais em relação a governos anteriores, e com certa continuidade (o que é fundamental), ainda apresentam várias limitações institucionais.

De um lado, pode-se citar, entre as várias realizações, medidas como as seguintes:

- aumento substancial dos recursos (o orçamento anual da FAPES, por exemplo, passou de algo em torno de $\mathrm{R} \$ 1$ milhão, em 2005, para mais de $\mathrm{R} \$ 40$ milhões em 2008);

- ampliação no número de bolsas para mestrado e doutorado concedidas;

- expansão no número de editais universais e temáticos para os pesquisadores;

- criação de editais para o setor produtivo (Pappe Subvenção, RHAE, etc.);

- instalação para breve do Centro de Pesquisa, Inovação e Desenvolvimento (CPID), importante para o desenvolvimento de Tecnologia Industrial Básica (TIB) no estado;

- instalação para breve da rede de Centros Vocacionais Tecnológicos (CVT’s) do Espírito Santo.

Por outro lado, várias limitações institucionais persistem. Um exemplo claro é o aumento substancial do orçamento da FAPES nos últimos anos, acima mencionado, mas sem o correspondente aumento no número de funcionários, que se mantém praticamente o mesmo durante o referido período. Outro exemplo pode ser buscado no próprio aumento dos recursos da FAPES, que foi direcionado em boa parte ao programa NOSSA BOLSA, relacionado com a concessão de bolsas em faculdades particulares (uma espécie de ProUni local), e, portanto mais voltado para a área de educação do que propriamente à de C\&T. Também pode ser citado o caso do NITES, criado mais recentemente, mas que também passa por dificuldades com carência de recursos humanos.

Outra deficiência institucional importante refere-se à ausência de uma instância clara de coordenação dos agentes, que vá além do mero estabelecimento de diretrizes, atuando como efetiva coordenadora dos atores do SCI. Este papel deveria ser exercido pela SECT, que também padece de crônica falta de funcionários.

Talvez por causa disso, Grassi et al. (2008), a partir de entrevistas com atores representativos do SCI, constataram uma certa dispersão de opiniões sobre o que deveria ser feito para se avançar na melhoria do SCI, o que evidencia um grau considerável de distanciamento entre os agentes, tornando ainda mais urgente uma coordenação ativa dos mesmos, que confronte e ouça opiniões 
buscando a elaboração de um diagnóstico o mais convergente possível sobre o que deve ser feito para a C\&T capixaba avançar em quantidade e qualidade.

Neste sentido, considera-se que o governo estadual não possui ainda instrumentos adequados de planejamento estratégico para dar conta desta complexa tarefa. A sua mais abrangente ferramenta de planejamento, o Plano de Desenvolvimento ES 2025 (SEP 2006), conta com apenas um dos seus 93 projetos estruturantes (o de número 58) diretamente voltado para a área de C,T\&I, e mesmo assim de forma muito superficial. A própria meta estabelecida neste plano é muito genérica, ao vincular investimentos em C\&T apenas em relação ao PIB capixaba. Passando-se ao Plano Plurianual (PPA) do atual governo estadual, constata-se que as áreas de C,T\&I não fazem parte de nenhum dos cerca de trinta projetos prioritários (o programa NOSSA BOLSA está incluído nesta lista, mas, como mencionado anteriormente, não é diretamente voltado para as áreas de C,T\&I). Portanto, conclui-se que não existe um planejamento estratégico detalhado para a área neste momento no governo estadual.

Do exposto até aqui, a partir da interpretação dos dados apresentados, tanto de patentes e artigos científicos como da PINTEC, em conjunto com as informações sobre o atual arcabouço institucional do estado para atividades de C,T\&I, pode-se considerar que o SCI se encontra ainda num estágio embrionário de desenvolvimento (gera pouca ciência, que se torna menos inovação ainda, se comparadas aos 2\% que o Espírito Santo ocupa no PIB brasileiro), revelando uma inserção deficiente da economia capixaba no atual paradigma tecno econômico. Como ressalva, deve-se destacar os investimentos em C\&T feitos pelo governo estadual nos últimos anos, que ainda não impactaram os indicadores de C\&T capixabas, embora as deficiências institucionais acima apontadas indiquem problemas na sua efetivação em termos de melhorias nos indicadores de C\&T atuais.

O resultado disso tudo é que, no que se refere à inovação, se considerarmos esta atividade como ir muito além da simples compra de máquinas e equipamentos mais modernos, chegando até ao desenvolvimento de P\&D, o Espírito Santo é movido por poucas "ilhas de excelência". A partir de entrevistas, Grassi et al. (2008) constataram que atualmente o estado apresenta um nível significativo de inovações no agronegócio (consequência da reconhecida atuação do INCAPER e de alguns empresários, em produtos como mamão, café, etc.), porém, pouca na indústria, concentrada em grandes empresas como a Aracruz Celulose. Isso evidentemente é preocupante em termos de potencial de crescimento econômico com agregação de valor nos próximos anos. 


\section{Análise das exportações capixabas sob a ótica da inten- sidade tecnológica}

No presente, a inserção externa da economia capixaba já apresenta reflexos do pouco conteúdo inovativo de suas atividades produtivas, o que caracteriza as exportações capixabas como sendo essencialmente compostas de produtos tipo commodities. Uma forma muito utilizada de se verificar esta situação é por meio da classificação das exportações segundo a intensidade tecnológica dos setores industriais, uma iniciativa da Organização para Cooperação e Desenvolvimento Econômico (OCDE), elaborada a partir da divisão entre os gastos com P\&D e o valor adicionado de cada setor (OCDE 2003).

Na referida classificação, além dos produtos industriais, existe ainda uma significativa gama de produtos classificados como não industriais que, de forma geral, incluem: animais vivos, produtos agrícolas e pecuários, pescados, minerais não metálicos, minerais metálicos, petróleo e gás natural, resíduos industriais e pedras preciosas em estado bruto. Com base nesse método, o MDIC (2007b) classificou as exportações brasileiras como mostra a Tabela 6. Em 2005, 79,5\% das exportações brasileiras foram de produtos industriais, sendo que $31,8 \%$ foram de produtos de alta e média-alta tecnologia. Por outro lado, 47,6\% das exportações nacionais foram de produtos industriais de média-baixa e baixa intensidade tecnológica e os demais 20,5\% foram de produtos não industriais.

A Tabela 6 mostra a classificação das exportações dos treze estados mais desenvolvidos do Brasil (em termos de participação no PIB nacional) em termos de intensidade tecnológica para o ano de 2005 em relação à pauta de exportação de cada estado. Alguns estados como Amazonas (99,3\%), Bahia (83,3\%), Pernambuco (87,7\%), São Paulo (96,8\%), Paraná $(88,8 \%)$, Rio Grande do Sul (83,3\%) e Santa Catarina (89,4\%) exportaram, em termos relativos, mais produtos industriais que o Brasil (79,5\%).

Todavia, foram poucos os estados que exportaram mais produtos de alta e média-alta tecnologia, em termos relativos, que o país $(31,8 \%)$ : somente Amazonas (86,9\%), Bahia (34,4\%), São Paulo (54,1\%), Paraná (34,6\%) e Rio Grande do Sul (32,7\%). Neste quesito, alguns estados apareceram em uma posição intermediária como Pernambuco $(17,4 \%)$, Minas Gerais (13,8\%), Rio de Janeiro $(14,4 \%)$ e Santa Catarina $(25,6 \%)$ e outros em uma posição desfavorável como Pará $(0,8 \%)$, Ceará (4,0\%), Goiás $(2,0 \%)$ e Espírito Santo $(0,2 \%)$ - este último, inclusive, possuía o menor percentual de exportação de produtos de alta e média-alta tecnologia em sua pauta de exportação dentre os treze estados mais desenvolvidos.

Ainda com relação aos produtos industriais, predominaram na pauta exportadora da economia capixaba em 2005 os produtos de média-baixa intensidade tecnológica (33\%) - o segundo maior percentual dentre os treze estados mais desenvolvidos -, com destaque para os produtos metálicos (24,3\%) e produtos 
minerais não metálicos (7,6\%). Em seguida, vem o setor de baixa intensidade tecnológica (14,6\%), com destaque para o setor de madeira, papel e celulose $(12,6 \%)$. No entanto, a principal especialização das exportações capixabas em 2005 foram os produtos não industriais, que são também de baixo conteúdo tecnológico (52\% do seu total exportado), o maior percentual dentre os estados mais desenvolvidos do país. ${ }^{8}$

Portanto, esses dados sobre exportações segundo a ótica da intensidade tecnológica mostram, assim como os dados apresentados na seção anterior, que o bom desempenho recente da economia capixaba em termos de crescimento não tem se traduzido em um desenvolvimento mais qualitativo de seu sistema produtivo, sobretudo o industrial. Isso porque em termos inovativos e de exportação consoante à intensidade tecnológica seu parque industrial apresenta baixo desempenho comparativamente à média nacional e, principalmente, em relação aos estados pertencentes à região do polígono. ${ }^{9}$ Apesar de importantes medidas de políticas públicas tomadas nos últimos anos, o fato de apresentar uma das mais baixas intensidades tecnológicas entre os estados mais desenvolvidos do país (o que já era esperado, dada a forte presença de commodities no perfil produtivo do estado) faz concluir que há espaço para o aumento do conteúdo tecnológico da produção e das exportações da economia capixaba, principalmente dos setores mais tradicionais (os casos da indústria metalmecânica, de móveis, confecções, mármore e granito, etc).

\footnotetext{
${ }^{8}$ Fazem parte dos produtos não industriais exportados pelo Espírito Santo raízes e tubérculos, nozes, pimenta, gengibre, mamão papaya e outras frutas, café, rochas ornamentais e minério de ferro.

${ }_{9}^{9}$ Dados sobre intensidade tecnológica das exportações devem ser olhados com cuidado. Na tabela 6, por exemplo, pode-se observar o caso do Amazonas, com alta porcentagem de produtos industriais de alta e média-alta tecnologia exportados, mas com baixos indicadores de C\&T, como mostrado na tabela 1. Como se sabe, isso é devido ao perfil produtivo do estado, concentrado na produção de produtos industriais considerados de alta tecnologia, mas que são apenas montados na Zona Franca de Manaus. Casos como este indicam o cuidado com o qual devem ser olhados os dados sobre intensidade tecnológica das exportações, mas não invalidam a análise do caso capixaba acima feita, cuja baixa intensidade tecnológica das exportações é acompanhada de um sistema de inovação que apenas recentemente começou a ser constituído.
} 
TABELA 6 - EXPORTAÇÃO DOS SETORES INDUSTRIAIS POR INTENSIDADE TECNOLÓGICA (2005): BRASIL E ESTADOS SELECIONADOS (PART. RELATIVA \%)

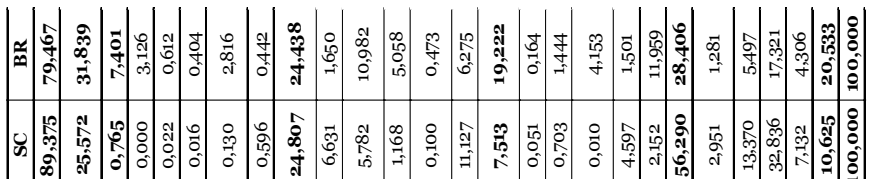

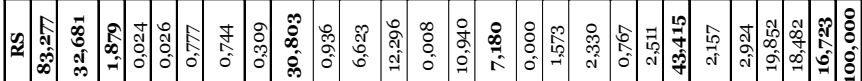

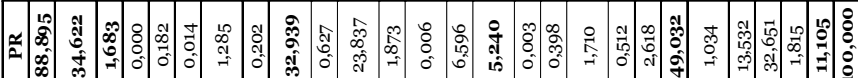

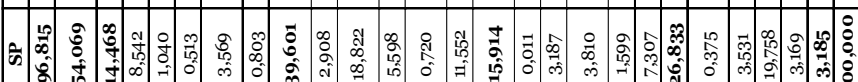

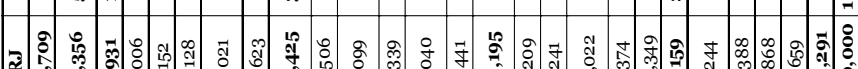

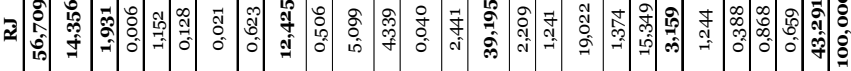

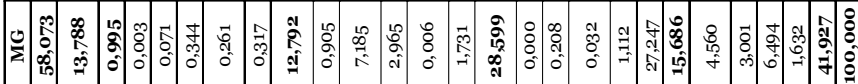

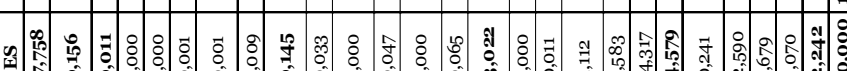

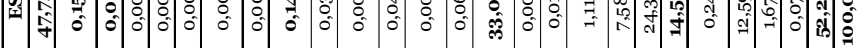

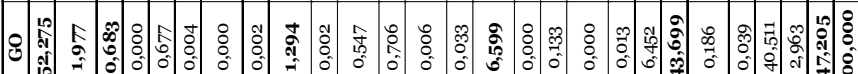

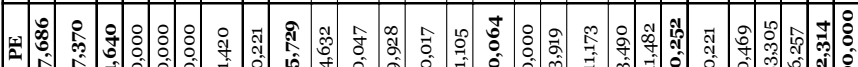

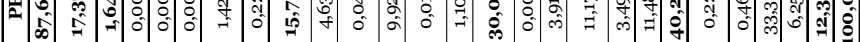

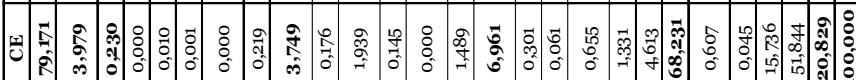
商

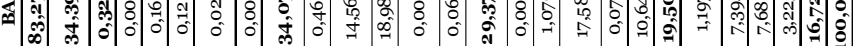

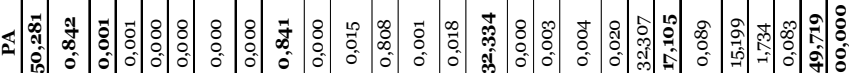

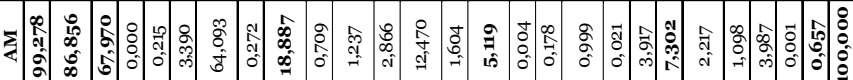

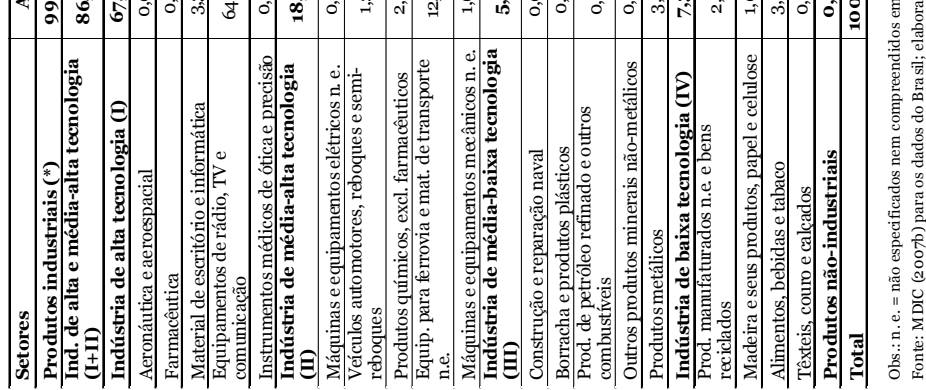




\section{Considerações finais}

Finalmente, é importante concluir que, embora o Espírito Santo venha apresentando taxas de crescimento econômico acima da média nacional nas últimas décadas, isso não foi suficiente para se inserir de forma efetiva no atual paradigma tecnoeconômico. Os motivos para isso, evidenciados a partir de dados sobre patentes, artigos científicos, os da PINTEC e os de intensidade tecnológica das exportações são:

1) a produção científica e tecnológica estadual é pequena em relação aos estados mais desenvolvidos (os do polígono), em proporção do PIB;

2) as empresas industriais do estado apresentaram um desempenho bastante modesto comparativamente aos estados da região do polígono nas atividades inovativas;

3) existe um insatisfatório nível de articulação entre instituições de ensino e pesquisa e o setor produtivo;

4) as taxas de cooperação com vistas à inovação também são diminutas;

5) as exportações do estado estão concentradas em produtos de baixa intensidade tecnológica e produtos não industriais (em grande parte, commodities).

Isso tudo está relacionado com o fato do Sistema de Inovação Capixaba ser ainda embrionário, com instituições funcionando há poucos anos e que apresentam problemas para atuarem de forma adequada, conforme mostrado anteriormente, evidenciando que no atual PTE das TICs o Espírito Santo ainda apresenta uma inserção deficiente, apesar dos importantes investimentos recentes. Cabe à sociedade capixaba e a seus representantes discutir se é realmente interessante destinar mais recursos para as áreas de C\&T, e, mais que isso, se estas áreas devem se tornar uma verdadeira prioridade, a partir de condições adequadas de funcionamento das instituições de apoio e com a elaboração de um detalhado planejamento estratégico para as mesmas.

Esta pesquisa parte do princípio de que, conforme a ampla evidência empírica demonstra, investimentos maiores nestas áreas podem ser importantes em termos de uma diversificação produtiva mais proveitosa em termos de geração de oportunidades de negócios para as empresas capixabas num futuro próximo, e tais investimentos se justificam ainda mais se levarmos em conta os limites de espaço urbano e meio ambiente que a atual prevalência da produção de commodities representa, sem contar que recursos como petróleo e gás são não renováveis.

Conclui-se, a partir deste conjunto de informações, que, em comparação com a parcela do PIB que o Espírito Santo ocupa no contexto nacional, há um espaço significativo para o crescimento das atividades de C,T\&I na economia 
capixaba, inclusive no que se refere ao papel das políticas públicas voltadas para estas atividades, que somente recentemente passaram a contar com um arcabouço institucional mínimo de apoio governamental. Espera-se que as medidas já colocadas em prática, em conjunto com condições adequadas de funcionamento das instituições de apoio e a elaboração de um planejamento estratégico para a melhor aplicação dos recursos, possam num futuro próximo reverter tal situação.

\section{Referências}

ALBAGLI, S. (1999). “Globalização e espacialidade: o novo papel do local.” In: CASSIOLATO, J. E. \& LASTRES, H. M.M. (eds.). Globalização e inovação localizada: experiências de sistemas locais no MERCOSUL. Brasília: IBICT/MCT. cap. 5 .

ALBUQUERQUE, E. M. \& SIMÕES, R. \& BAESSA, A. \& CAMPOLINA, B. \& SILVA, L. (2002). "A distribuição espacial da produção científica e tecnológica brasileira: uma descrição de estatísticas de produção local de patentes e artigos científicos." Revista Brasileira de Inovação 1 (2): 225-251.

\& SILVA, L. (2005). "Interação entre ciência e tecnologia no Brasil: notas sobre a relação entre P\&D industrial e a importância da universidade para as empresas.” Belo Horizonte-MG: CEDEPLAR/UFMG. Texto para discussão 253.

CASSIOLATO, J. E. \& LASTRES, H. M.M. (eds.). (1999). Globalização e inovação localizada: experiências de sistemas locais no MERCOSUL. Brasília: IBICT/ MCT.

COHEN, W. M., LEVINTHAL, D. A. (1989). "Innovation and learning: the two faces of R\&D”. The Economic Journal, 99: 569-596.

COUTINHO, L. \& FERRAZ, J. C. (coords.). (1994). Estudo da competitividade da indústria brasileira. Campinas: Papirus.

DE NEGRI, J. A. \& SALERNO, M. S. \& CASTRO, A. B. (2005). "Inovações, padrões tecnológicos e desempenho das firmas industriais brasileiras." In: DE NEGRI, J. A. \& SALERMO, M. S. (orgs.). Inovações, padrões tecnológicos e desempenho das firmas industriais brasileiras. Brasília: IPEA. cap. 1.

DINIZ, C. C. (2001). “Globalização, escalas territoriais e política tecnológica regionalizada no Brasil.” Belo Horizonte: CEDEPLAR/UFMG. Texto para discussão 168.

(2002). "Repensando a questão regional brasileira: tendências, desafios e caminhos." In: CASTRO, A. C. (org.). Desenvolvimento em debate: painéis do desenvolvimento brasileiro. Rio de Janeiro: Manaud/BNDES, v. 3. pp. 239-274.

, CROCCO, M. A. (1996). "Reestruturação econômica e impacto regional: a nova configuração da indústria brasileira”. Nova Economia, 6(1).

\& GONÇALVES, E. (2001). "Knowledge economy and regional development in Brazil.”In Les Troisièmes Journées de la Proximité - The Third Congress on Proximity, Paris, França. 
DOMINGUES, E. \& RUIZ, R. (2006a). “Aglomerações econômicas no polígono industrial brasileiro: escalas, estruturas e diferenciais.” Anais do XII Seminário sobre a Economia Mineira, Diamantina.

\& _ (2006b). "Aglomerações industriais e tecnológicas: origem do capital, inovação e localização.” Economia e Sociedade 15 (3): 515-543.

DOSI, G. (1982) “Technological paradigms and technological trajectories." Research Policy, 11 (3): 147-162.

. (1984) Technical change and industrial transformation. New York: St. Martin Press.

. (1988). "The nature of the innovative process.” In: DOSI, G. \& FREEMAN, C \& NELSON, R. \& SILVERBERG, G. \& SOETE, L. (eds.). Technical change and economic theory. London: MERIT. pp. 221-238.

FLORIDA, Richard. (1995). “Toward the learning region.” Futures 27 (5): 527536.

FREEMAN, C. \& PEREZ, C. (1988). "Structural crises of adjustment: business cycles and investment behavior.” In: DOSI, G. \& FREEMAN, C \& NELSON, R. \& SILVERBERG, G. \& SOETE, L. (eds.). Technical change and economic theory. Londres: Pinter.

\& SOETE, L. (1997). The economics of industrial innovation. 3. ed. London: Pinter.

FURTADO, A. T. \& CARVALHO, R. Q. (2005). "Padrões de intensidade tecnológica da indústria brasileira: um estudo comparativo com os países centrais.” São Paulo em Perspectiva 19 (1): 70-84.

GONÇALVES, E. (2007). "O padrão espacial da atividade inovadora brasileira: uma análise exploratória.” Estudos Econômicos 37 (2): 405-433.

, LEMOS, M. B., DE NEGRI, J. (2005). Determinantes do esforço inovador no Brasil. In: XXXIII Encontro Nacional de Economia, Natal.

GRASSI, R. \& CAÇADOR, S. \& HOFFMAN, A. \& BISSOLI, C. (2008). Desafios estratégicos para o Espírito Santo nas áreas de Ciência, Tecnologia e Inovação (C,T\&I): diagnóstico e diretrizes de políticas públicas a partir das teorias de Organização Industrial e Desenvolvimento Regional (Relatório Final). Vitória: Grupo de Estudos em Organização Industrial da Universidade Federal do Espírito Santo. (mimeo.)

IBGE - INSTITUTO BRASILEIRO DE GEOGRAFIA E ESTATÍSTICA. (2007). Pesquisa de Inovação Tecnológica (PINTEC) 2005. Rio de Janeiro: IBGE.

IPEADATA. (2007). “Dados das Unidades da Federação sobre o PIB de 2004.” URL: http://www.ipeadata.gov.br. Acesso em: 10 de janeiro de 2007.

JAFFE, Adam B. (1989) "Real effects of academic research." American Economic Review 79 (5): 957-970.

JOHNSON, B. \& LUNDVALL, B.A. (2000). Promoting innovation systems as a response to the globalising learning economy. Rio de Janeiro: BNDES/FINEP/ FUJB.

KANNEBLEY Jr., S. \& PORTO, G. \& PAZELLO, E. (2004). "Inovação na indústria brasileira: uma análise exploratória a partir da PINTEC." Revista Brasileira de 
Inovação 3 (1): 87-128.

KLEVORICK, A. \& LEVIN, R. \& NELSON, R., WINTER, S. (1995). "On the sources and significance of inter-industry differences in technological opportunities.” Research Policy 24: 185-205.

KUPFER, D. \& HASENCLEVER, L. (orgs.). (2002). Economia Industrial: fundamentos teóricos e práticas no Brasil. $9^{\text {a }}$ reimpressão. Rio de Janeiro: Elsevier.

LA ROVERE, R. L. (2006). “Paradigmas e trajetórias tecnológicas.” In: PELAEZ, V. \& SZMRECSÁNYI, T. (orgs.). Economia da inovação tecnológica. São Paulo: Editora Hucitec/Ordem dos Economistas do Brasil. cap. 12.

LUNDVALL, B.A. (1992). “Introduction.” In: LUNDVALL, B.A. (ed.). National systems of innovation: towards a theory of innovation and interactive learning. London: Pinter. 1-19.

; JOHNSON, B. (1994). “The learning economy.” Journal of Industrial Studies 1 (2): 23-42.

MINISTÉRIO DA CIÊNCIA E TECNOLOGIA (MCT). (2007). "Indicadores nacionais e estaduais de ciência e tecnologia.” URL [On line]: http://www.mct.gov.br. Acesso em: 01 de dezembro de 2007.

MINISTÉRIO DO DESENVOLVIMENTO, INDÚSTRIA E COMÉRCIO EXTERIOR (MDIC). (2007a). "Estatísticas de comércio exterior por Unidade da Federação." URL: http://www.mdic.gov.br. Acesso em: 01 de dezembro de 2007.

. (2007b). "Exportação brasileira dos setores industriais por intensidade tecnológica: 1996-2005.” URL: http://www.mdic.gov.br. Acesso em: 01 de agosto de 2007.

MOTA, F. C. M. (1997). Política industrial e instituições locais: a importância de uma política cientifica e tecnológica para a (re) estruturação industrial no Estado do Espírito Santo. Dissertação de Mestrado, Universidade Federal do Espírito Santo, Programa de Pós-Graduação em Economia.

(2007). "Avaliação da experiência capixaba de ciência, tecnologia e inovação.” Parcerias Estratégicas 25: 93-114.

NELSON, R. \& WINTER, S. (1977). "In search of a useful theory of innovation." Research Policy 6 (1): 36-76.

$\&$ Harvard University Press.

. (1982). An evolutionary theory of economic change. Cambridge:

; \& ROSENBERG, N. (1993). "Technical innovation and national systems." In: NELSON, R. (ed.). National Innovation Systems: a comparative analysis. New York, Oxford: Oxford University. pp. 3-21.

NUNES, D. (2004). Cooperação, aprendizado e capacitação inovativa das empresas de confecções do arranjo produtivo em Colatina, ES. Vitória: Dissertação de Mestrado, Universidade Federal do Espírito Santo, Programa de Pós-Graduação em Economia.

OINAS, P. \& MALECKI, E (1999). “Spatial innovations systems.” In: MALECKI, E. \& OINAS, P. Making connections, technological learning and regional economic change. London: Aldershot-Ashgate.

ORGANIZATION FOR ECONOMIC COOPERATION AND DEVELOPMENT 
(OECD). (1997). OSLO Manual: proposed guidelines for collecting and interpreting technological innovation data. Paris: OECD: Statistical Office of the European Communities; Washington, D.C.: OECD Washington Center. . (2003). Science, Technology and Industry Scoreboard. Paris: OECD.

PAVITT, K. (1984). "Sectoral patterns of technical change: towards a taxonomy and a theory." Research Policy 13 (6): 343-373.

PORTER, M. (1990). A vantagem competitiva das nações. Rio de Janeiro: Campus.

POSSAS, M. L. (2002). “Concorrência schumpeteriana.” In: KUPFER, D. \& HASENCLEVER, L. (orgs.). Economia Industrial: fundamentos teóricos e práticas no Brasil. 9. reimpressão. Rio de Janeiro: Elsevier. cap. 17.

ROSENBERG, N. (1982). Inside the black box: technology and economics. Cambridge: Cambridge University Press.

SANTOS Jr., J. L. (2005). Logística de comércio exterior: estratégias inovativas de alguns operadores capixabas frente ao paradigma das tecnologias da informação e comunicação. Vitória: Dissertação de Mestrado, Universidade Federal do Espírito Santo, Programa de Pós-Graduação em Economia.

SCHUMPETER, J. (1964) [1911]. Business cycles: a theoretical, historical and statistical analysis of the capitalist process. New York: McGraw-Hill Books.

. (1960) [1934]. Teoria do desenvolvimento econômico. Rio de Janeiro: Fundo de Cultura.

. (1961) [1943]. Capitalismo, socialismo e democracia. Rio de Janeiro: Fundo de Cultura.

SECRETARIA DE ESTADO DE ECONOMIA E PLANEJAMENTO (SEP). (2006). Espírito Santo 2025: plano de desenvolvimento. Vitória: SEP/MACROPLAN.

SIMÕES, R. \& OLIVEIRA, A. \& GITIRANA, A. \& CUNHA, J. \& CAMPOS, M. \& CRUZ, W. (2005). "A geografia da inovação: uma metodologia de regionalização das informações de gastos em P\&D no Brasil.” Revista Brasileira de Inovação 4 (1): 157-185.

VIEIRA, A. (2004). Inovação na cultura do mamão: geração e difusão do conhecimento. Vitória: Dissertação de Mestrado, Universidade Federal do Espírito Santo, Programa de Pós-Graduação em Economia.

VILLASCHI FILHO, A. (1996). Difusão de automação de base microeletrônica e de novas técnicas organizacionais junto à pequenas e médias empresas: análise do caso capixaba. Vitória: SEBRAE-ES.

. (1999). "Alguns elementos dinâmicos do sistema capixaba de inovação." In: LASTRES, H. M.M., CASSIOLATO, J. E. (orgs.). Globalização e inovação localizada: experiências de sistemas locais no MERCOSUL. Brasília: IBICT. pp. 199-244.

VIOTTI, E. \& BAESSA, A. \& KOELLER, P. (2005). "Perfil da inovação na indústria brasileira: uma comparação internacional.” In: DE NEGRI, J. A., SALERNO, M. S. (orgs.). Inovações, padrões tecnológicos e desempenho das firmas industriais brasileiras. Brasília: IPEA. cap. 16. 
CAÇADOR, S.B. \& GRASSI, R.A. O Espírito Santo no atual paradigma tecnoeconômico...

Recebido em: 18 de fevereiro de 2009

Primeira resposta em: 26 de março de 2009

Aceite em: 25 de abril de 2009 